\title{
Impact of Body Mass Index, Age and Tobacco Use on the Outcomes of Immediate Breast Reconstruction with Implants and Acellular Dermal Matrix
}

\author{
L. Mata Ribeiro ${ }^{1, \odot ~ R i t a ~ P . ~ M e i r e l e s ~}{ }^{2}$ Irís M. Brito ${ }^{2}$ Patrícia M. Costa ${ }^{1}$ Marco A. Rebelo ${ }^{3}$ \\ Rui F. Barbosa ${ }^{3}$ Miguel P. Choupina ${ }^{3}$ Carlos J. Pinho ${ }^{3}$ Matilde P. Ribeiro ${ }^{3}$
}

${ }^{1}$ Department of Plastic and Reconstructive Surgery, Centro Hospitalar Universitário Lisboa Central, Hospital São José Lisbon, Portugal

2Department of Plastic and Reconstructive Surgery, Centro Hospitalar e Universitário de Coimbra, Coimbra, Portugal

${ }^{3}$ Department of Plastic and Reconstructive Surgery, Instituto Português de Oncologia do Porto, Porto, Portugal

\author{
Address for correspondence Luís Mata Ribeiro, MD, Department \\ of Plastic and Reconstructive Surgery, Hospital São José, \\ Centro Hospitalar Lisboa Central, Rua José António Serrano, \\ 1150-199 Lisboa, Portugal (e-mail: Luis1989ribeiro@hotmail.com).
}

\begin{abstract}
Background This study aimed to analyze the effect of body mass index (BMI), age, and tobacco use on alloplastic breast reconstruction.

Methods We conducted a retrospective study of patients who submitted to immediate breast reconstructions with an anatomical implant and acellular dermal matrix in a single center between 2016 and 2018. Outcomes evaluated included immediate complications, early complications, reinterventions, readmissions, and reconstruction failure. Patients were divided into two groups concerning each potential risk factor (BMI < or $\geq 25$; age < or $\geq 50$ years; and smokers vs nonsmokers). Simple descriptive statistics and univariate analysis were performed.

Results A total of 101 breast reconstructions (73 patients) were included in the analysis. The mean BMI was 24 , and the mean age was 44.5 years old. Smokers accounted

Keywords

- alloplastic

- ADM

- smoking

- BMI

- age

- immediate breast reconstruction

- implant for 14 breast reconstructions (13.9\%). The rate of early infections, mastectomy flap necrosis, and implant removal was significantly higher in overweight patients. The total volume of breast drainage was higher in the age $\geq 50$ years group. Smoking did not alter the outcomes.

Conclusions $\mathrm{ABMI} \geq 25$ is a risk factor for early infections and reconstructive failure. Age $\geq 50$ years is associated with a higher volume of breast drainage but does not seem to impact the success of the reconstruction. Smoking does not appear to affect the outcomes significantly in this type of reconstruction. Surgeons should consider delaying the reconstruction or using autologous tissue when patients are overweight.
\end{abstract}

\section{Introduction}

Breast reconstruction after mastectomy is nowadays a routine procedure worldwide. The reconstruction can be done

published online September 27, 2021
DOI https://doi.org/

$10.1055 / \mathrm{s}-0041-1735422$

ISSN $0970-0358$ using autologous tissues or breast implants/expanders. In the last decades, the trend has shifted from autologous to implant-based reconstruction, constituting more than $70 \%$ of all breast reconstructions. ${ }^{1,2}$
(C) 2021. Association of Plastic Surgeons of India.

This is an open access article published by Thieme under the terms of the Creative Commons Attribution-NonDerivative-NonCommercial-License, permitting copying and reproduction so long as the original work is given appropriate credit. Contents may not be used for commercial purposes, or adapted, remixed, transformed or built upon. (https://creativecommons.org/licenses/by-nc-nd/4.0/).

Thieme Medical and Scientific Publishers Pvt. Ltd. A-12, 2nd Floor, Sector 2, Noida-201301 UP, India 
The recent development of acellular dermal matrixes (ADM) allowed surgeons to attempt an immediate single-stage breast reconstruction, providing better lower pole coverage and inframammary fold definition, improved aesthetic results, and reduced capsular contracture rates. ${ }^{1,3,4}$ Despite some of these findings, the data regarding the safety and efficacy of ADM is still conflicting. ${ }^{5}$

Complications in breast reconstruction can cause morbidity in several ways but the most important one is the delay of subsequent oncologic treatment. ${ }^{6}$ Several studies have attempted to identify risk factors for alloplastic breast reconstruction, but few of them focused on immediate reconstruction with implants and ADM.?

Smoking and excess weight are universally considered risk factors for surgical complications. ${ }^{8}$ This is also observed with regard to breast reconstruction but mainly in autologous reconstruction. The results in implant-based reconstructions are conflicting. ${ }^{2,6}$ The impact of age is also unknown, with several studies including patients from different age groups showing similar outcomes. ${ }^{9,10}$

The purpose of the present study was to better characterize the effect of body mass index (BMI), age, and tobacco use on immediate implant (and ADM) breast reconstructions. We sought to compare the outcomes and the incidence of postoperative complications between cohorts with different expressions of those risk factors. This information is crucial to ascertain, since it aids in the decision-making of the best reconstructive method to elect and permits more appropriate patient counselling concerning the perioperative risk of complications.

\section{Methods}

The authors conducted a retrospective study of patients submitted to immediate implant-based breast reconstruction between October 2016 and December 2018 (26 months), at Instituto Português de Oncologia-Porto (IPO Porto). All patients who submitted to skin-sparing mastectomy (for oncologic treatment or as a prophylactic intervention) and reconstruction with anatomical breast implant plus ADM at the same time were included in this institutional review. Patients who submitted to immediate reconstruction with tissue expanders or autologous flaps, submitted to delayed reconstruction, or those who had no reconstructive procedure were excluded from the study.

Oncological surgeons performed all mastectomy interventions. Five senior plastic surgeons performed breast reconstructions. The ADM (Native - MBP Biologics, Neustadt-Glewe, Germany, license holder Decomed, Marcon, Venezia, Italy) was used as an inferior sling for the breast implant. Pectoralis major muscle was detached from the ribs inferolaterally, and the ADM was fixed to the inframammary fold and the inferior border of the muscle following its lateral contour. The breast implant was introduced through the central pocket left open and then placed behind the pectoralis major and the ADM, and these structures were closed over the implant with absorbable sutures. Two drains were used, one in the retropectoral space and the other in the subcutaneous space.
We reviewed hospital records independently for all patients, collecting data pertaining to patient demographics such as age, BMI, genetic risk, smoking history, diabetes mellitus (DM), and hypertension (HTN). We also noted whether the reconstructions were unilateral or bilateral. Outcomes assessed included major immediate complications (hematoma, infection requiring intravenous pharmacological treatment, mastectomy flap necrosis and implant extrusion), early complications (infection, hematoma, implant extrusion, seroma formation), reinterventions (during the same hospitalization), readmissions, need for implant removal (anytime), total breast drainage, and duration of breast drainage. Immediate complications were categorized as major if they had caused a reintervention or additional treatment prolonging the hospitalization time. Complications occurring within the first 3 months postoperatively after discharge were classified as early complications. The outcomes were collected with a follow-up period of at least 6 months (6-12 months).

To stratify the patients by risk regarding BMI, they were placed in two different cohorts-normal weight (BMI $<25 \mathrm{~kg} / \mathrm{m}^{2}$ ) and overweight $\left(\mathrm{BMI} \geq 25 \mathrm{~kg} / \mathrm{m}^{2}\right)$. With respect to smoking history, patients were classified into nonsmokers (no history of regular tobacco use or ex-smokers) or smokers (active smokers in the last month). With regard to age, patients were subdivided into younger than 50 years or those who were 50 or more years.

Statistical analysis was performed with SPSS software (version 24). Median and percentiles P25 and P75 were used to present descriptive results. With respect to categorical variables, data are shown with frequencies $(n)$ and percentages (\%). Chi-square and Fisher exact test were used to search for associations between categorical variables. As far as continuous variables were concerned, Mann-Whitney test was used to detect any associations. Significance was considered for $p<0.05$.

\section{Results}

Seventy-three women underwent immediate breast reconstruction with implant plus ADM following mastectomy during the study period. Forty-five patients were submitted to unilateral and 28 to bilateral reconstructive procedures, producing a total of 101 breast reconstructions. The mean BMI was 24 and the mean age 44 was years. Fourteen breast reconstructions were conducted on smokers (13.9\%).

\section{BMI}

Sixty (59.4\%) breast reconstructions were performed on patients in the normal weight group (BMI $<25 \mathrm{~kg} / \mathrm{m}^{2}$ ) and $41(40.6 \%)$ in the overweight group (BMI $\geq 25 \mathrm{~kg} / \mathrm{m}^{2}$ ). With regard to the latter group, five patients were obese (BMI > $30 \mathrm{~kg} / \mathrm{m}^{2}$ ).

There was no significant statistical difference between the two groups in relation to age, genetic risk, smoking history, and comorbidities ( - Table 1 ). . Despite this, the BMI $>25$ group had more patients $>50$ years old $(31.7 \%$ vs. $18.3 \%)$ and more smokers (19.5\% vs. $10 \%)$. Bilateral procedures occurred more frequently in patients with BMI $\geq 25(p=0.032)$ (-Table $\mathbf{1})$. 


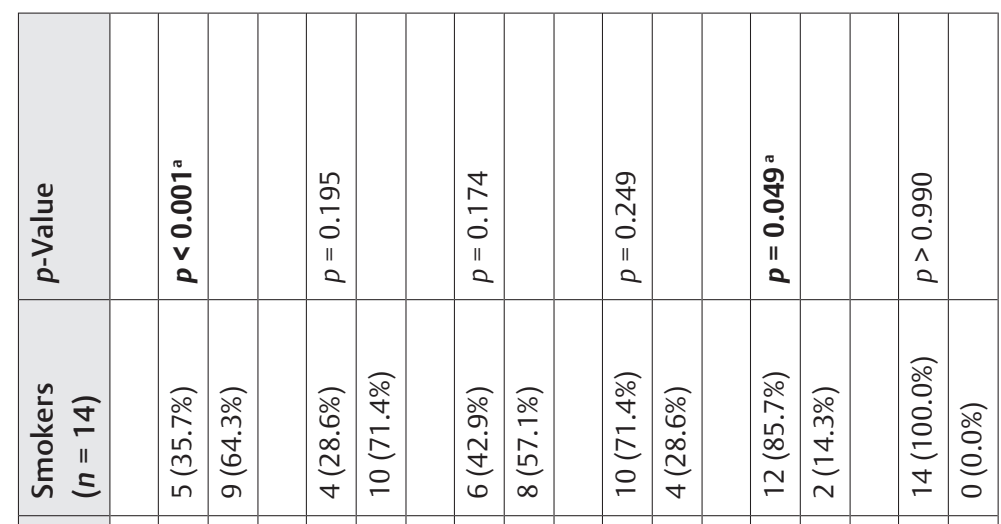

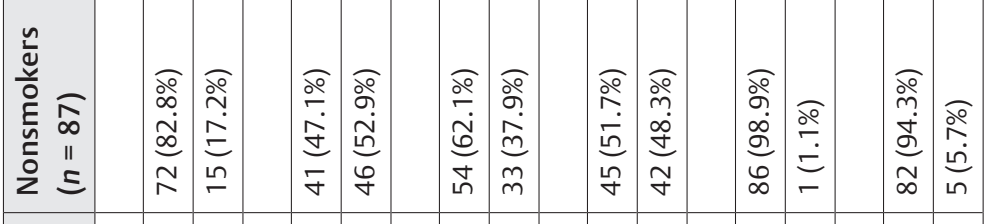

\begin{tabular}{|c|c|c|c|c|c|c|}
\hline $\begin{array}{l}\frac{0}{3} \\
\frac{\pi}{n} \\
\frac{1}{2}\end{array}$ & 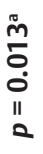 & $\begin{array}{l}\bar{̃} \\
\overline{0} \\
11 \\
0\end{array}$ & $\begin{array}{l}\frac{\pi}{2} \\
\dot{0} \\
\dot{v} \\
v \\
0\end{array}$ & $\begin{array}{l}{ }^{*} \\
0 \\
\dot{0} \\
v \\
0\end{array}$ & $\begin{array}{l}\overline{0} \\
h n \\
0 \\
11 \\
0\end{array}$ & $\begin{array}{l}\frac{\pi}{0} \\
\overline{0} \\
0 \\
\text { II } \\
0\end{array}$ \\
\hline & & & & & & \\
\hline
\end{tabular}

\begin{tabular}{|c|c|c|c|c|c|c|c|c|c|c|c|c|}
\hline 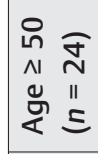 & $\begin{array}{l}\stackrel{\circ}{\hat{\circ}} \\
\dot{b} \\
\stackrel{0}{0} \\
0 \\
-\end{array}$ & 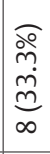 & 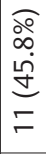 & 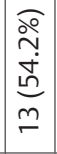 & 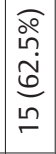 & $\begin{array}{l}\widehat{ㅇ} \\
\text { ஸे } \\
\hat{n} \\
\text { an }\end{array}$ & 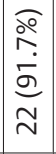 & $\begin{array}{l}\stackrel{\widehat{\circ}}{\grave{m}} \\
\stackrel{\infty}{\sim} \\
\sim\end{array}$ & 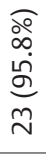 & 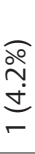 & 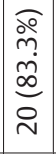 & 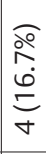 \\
\hline 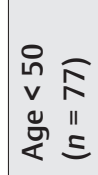 & 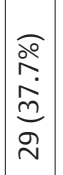 & 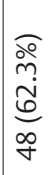 & 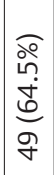 & 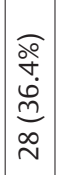 & 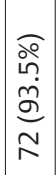 & 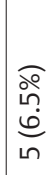 & 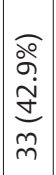 & 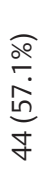 & 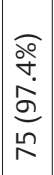 & $\begin{array}{l}\text { do } \\
\stackrel{d}{d} \\
\text { de }\end{array}$ & 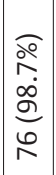 & 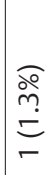 \\
\hline 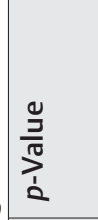 & $\begin{array}{l}\bar{N} \\
\overline{0} \\
11 \\
\alpha\end{array}$ & & $\begin{array}{l}\tilde{N} \\
\tilde{o} \\
0 \\
0 \\
\text { II } \\
\text { a }\end{array}$ & & 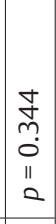 & & $\begin{array}{l}0 \\
\frac{1}{2} \\
0 \\
11 \\
0\end{array}$ & & $\begin{array}{l}\stackrel{\bigcirc}{\circ} \\
\stackrel{2}{0} \\
\wedge \\
0\end{array}$ & & $\begin{array}{l}\stackrel{\llcorner}{\varrho} \\
\stackrel{0}{0} \\
0 \\
11 \\
0 \\
0\end{array}$ & \\
\hline
\end{tabular}

ก

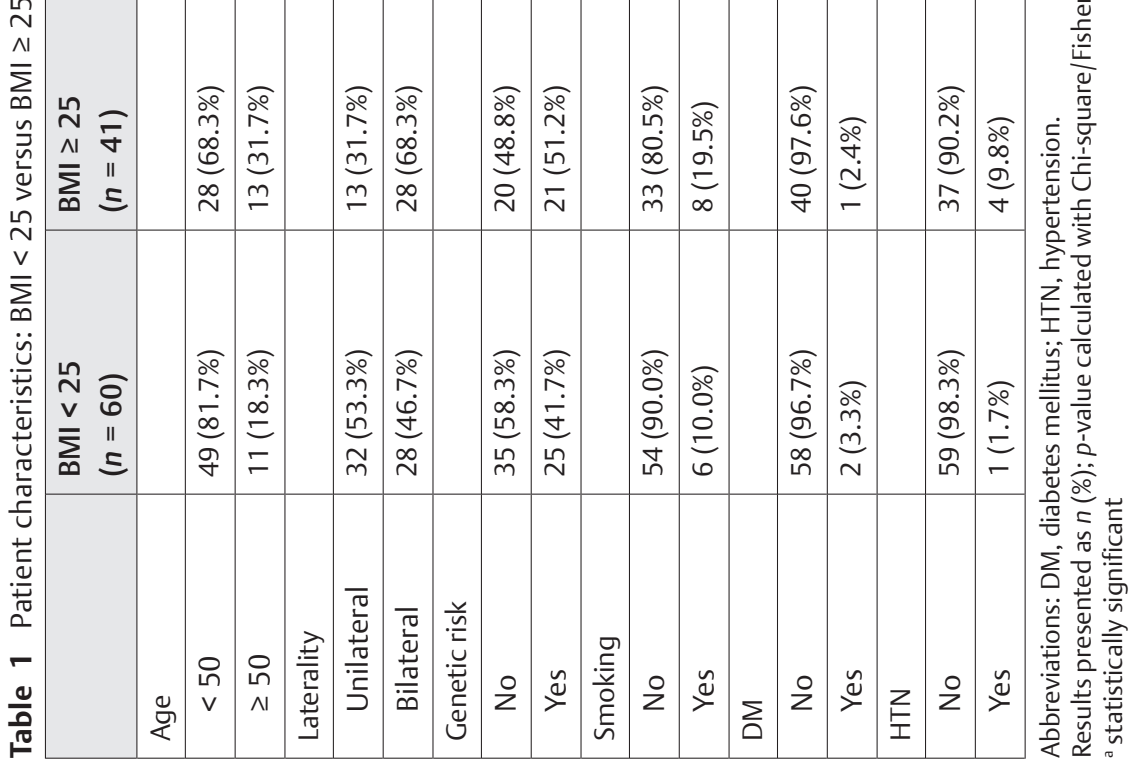




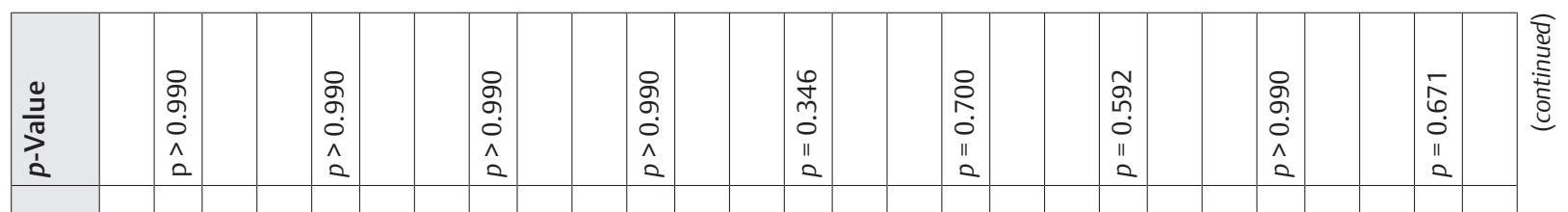

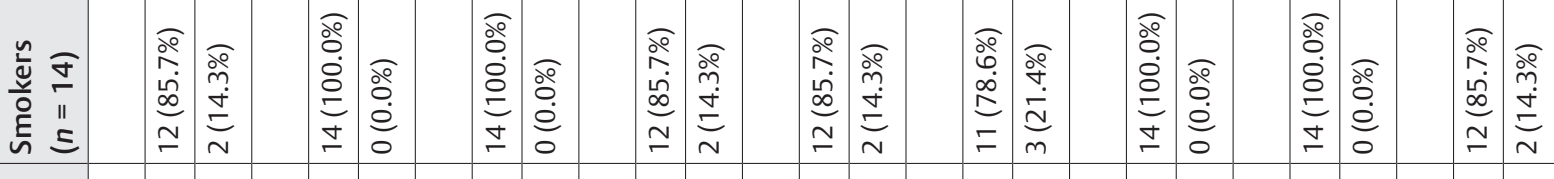

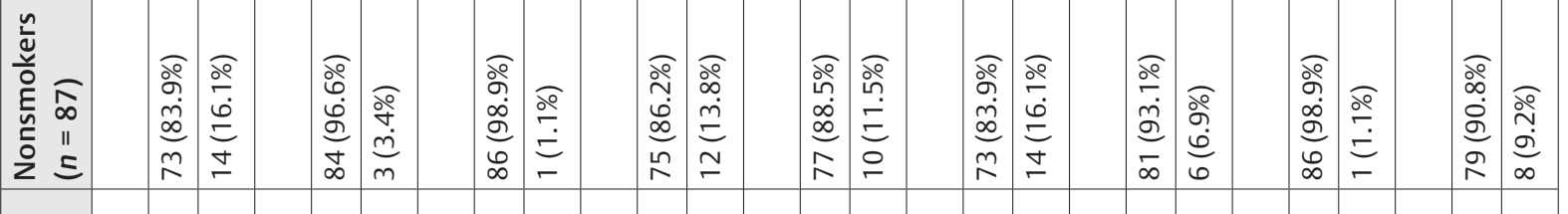

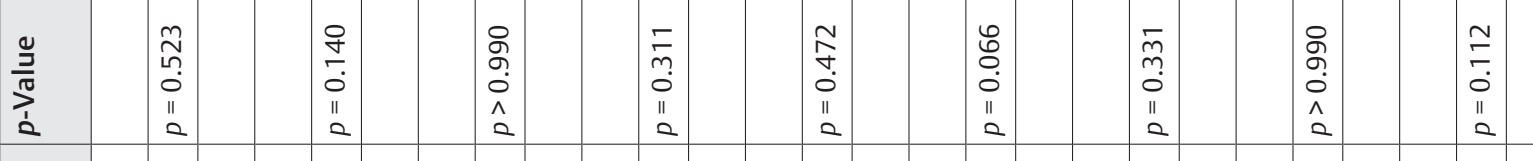

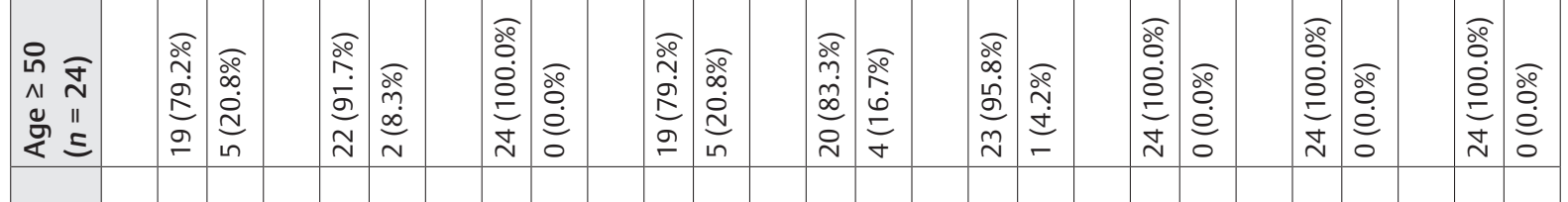

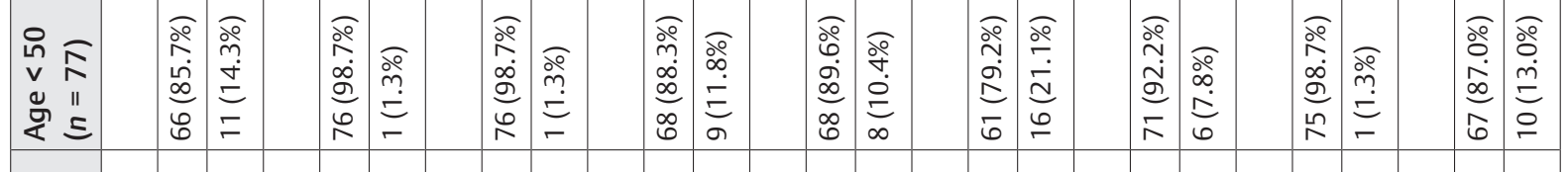

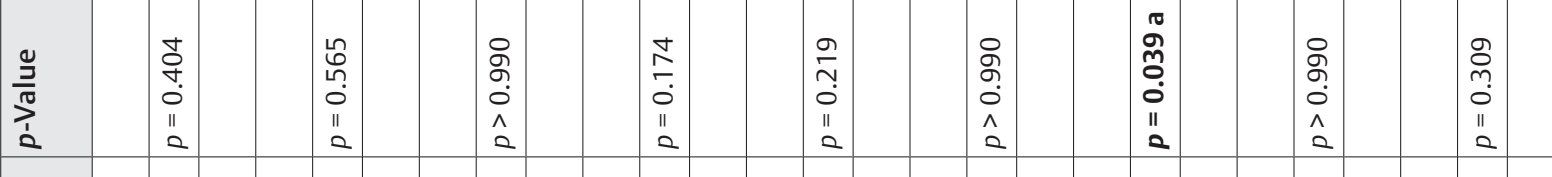

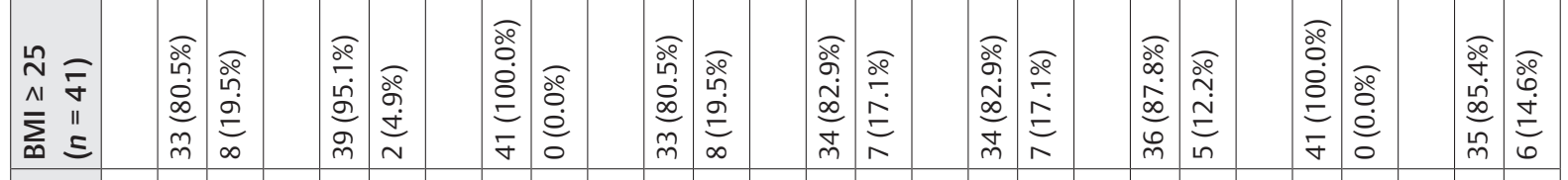

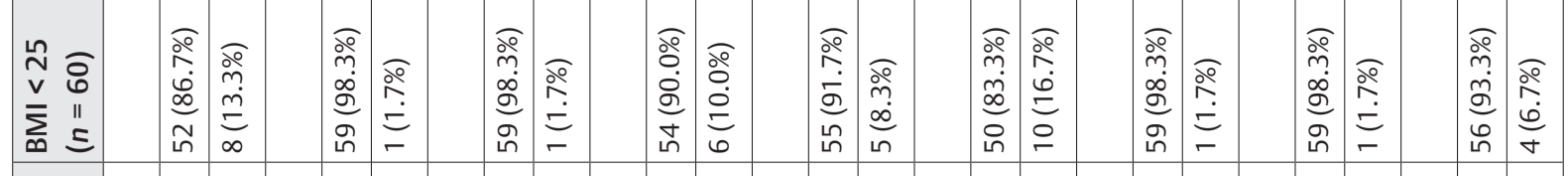

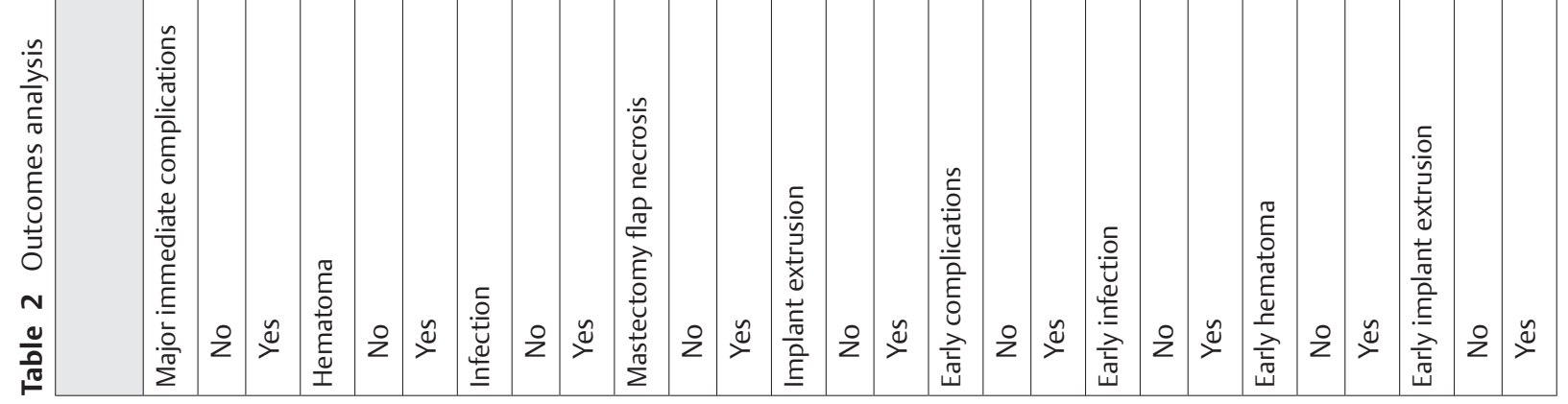




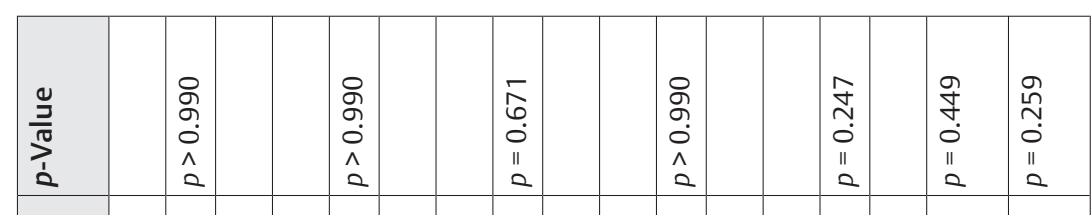

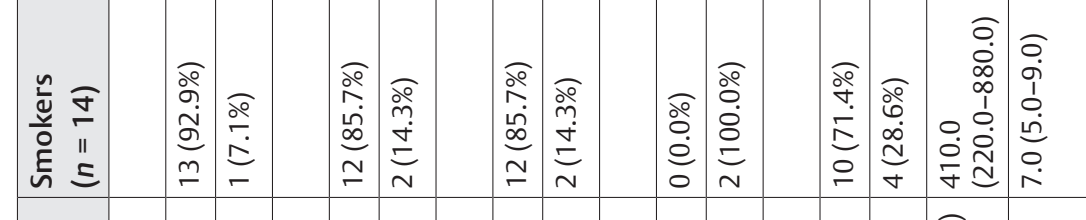

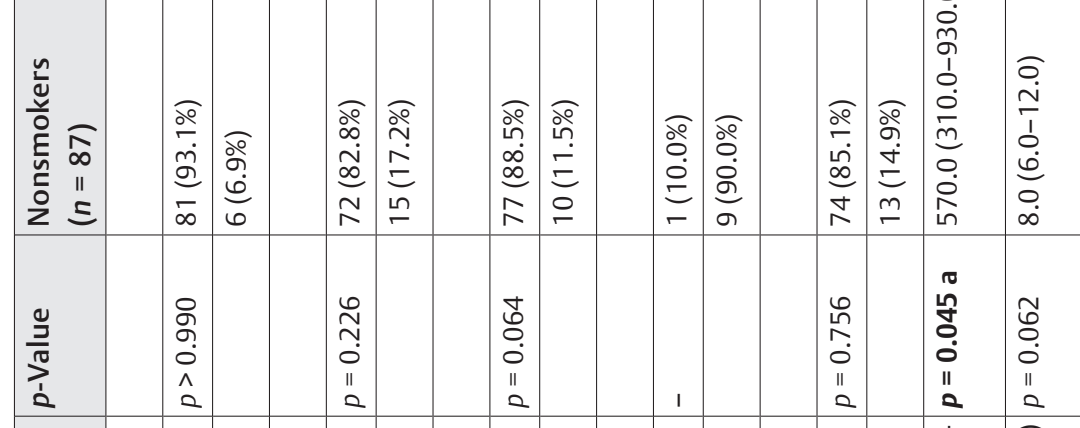

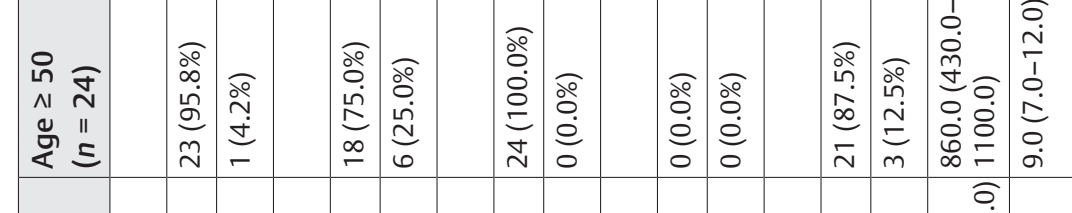

\begin{tabular}{|c|c|c|c|c|c|c|c|c|c|c|c|c|}
\hline 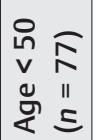 & & 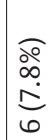 & 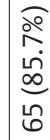 & 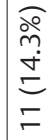 & 6 & 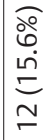 & $=$ & & & & 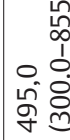 & ف \\
\hline
\end{tabular}

\begin{tabular}{|c|c|c|c|c|c|c|}
\hline$\frac{0}{\frac{0}{n}}$ & 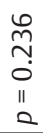 & 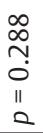 & 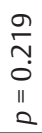 & $\begin{array}{l}8 \\
0 \\
o \\
0 \\
1 \\
a\end{array}$ & $\begin{array}{l}\text { ñ } \\
\text { o. } \\
\text { II } \\
0\end{array}$ & $\begin{array}{l}8 \\
\vdots \\
0 \\
11 \\
0\end{array}$ \\
\hline
\end{tabular}

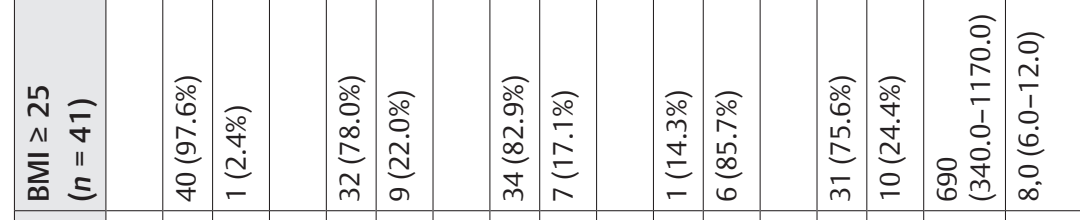

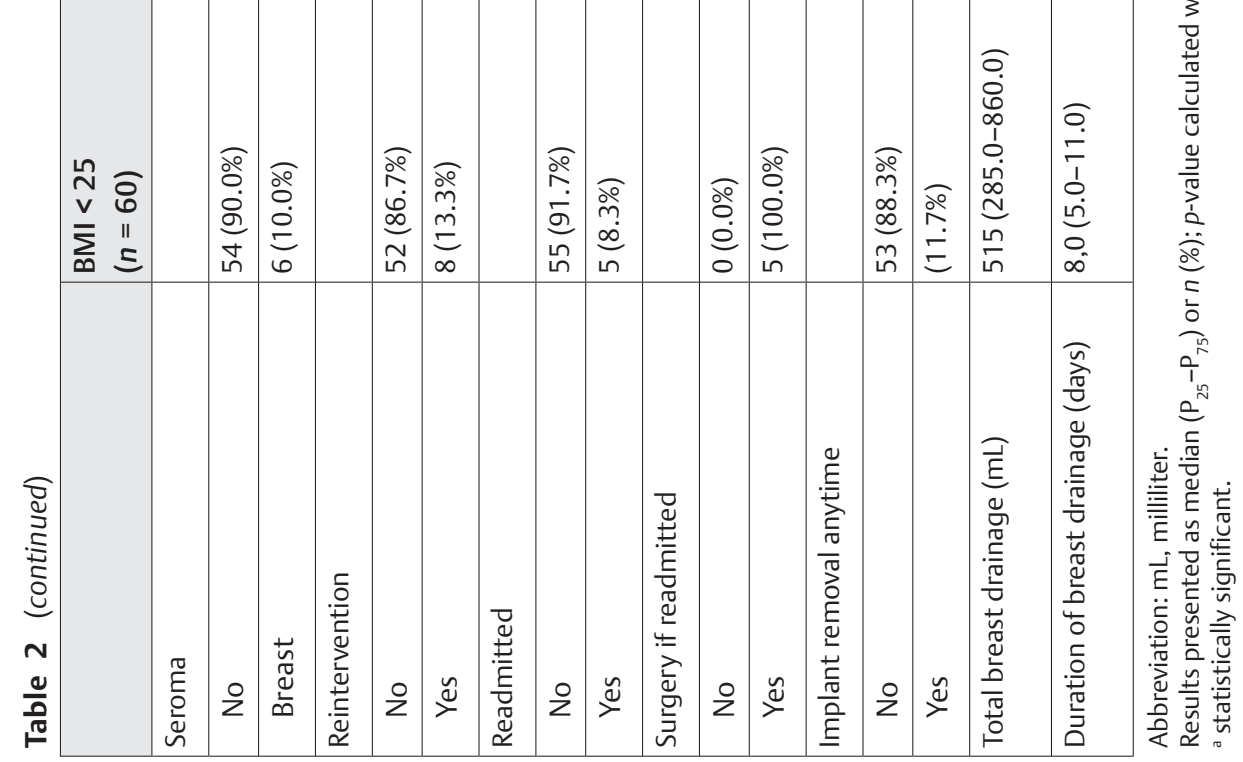


With regard to outcomes, early infection was more prevalent in the group of patients with BMI $\geq 25(p=0.006)$. This was the only statistically significant result ( $\mathbf{- T a b l e ~} \mathbf{2}$ ). Overweight patients were also associated with higher total breast drainage volume $(p=0.06)$, higher rates of mastectomy flap necrosis ( $19.5 \%$ vs. $10 \% ; p=0.17$ ), and higher chances of implant removal anytime ( $24.4 \%$ vs. $11.7 \%$; $p=0.09$ ).

\section{Age}

Of the 101 breast reconstructions, 75 occurred in patients younger than 50 years and 24 in patients aged $\geq 50$ years (three of them were older than 60 years).

Patient demographics and comorbidities are shown in - Table 1. Bilateral procedures and genetic risk were more prevalent in the age group $<50$ years $(p=0.013$ and $p<0.001$, respectively). On the opposite, HT and smoking were mainly associated with the group $\geq 50$ years $(p=0.011$ and $p<0.001$, respectively).

Regarding outcomes (- Table 2 ), the only result with statistical significance was the total volume of breast drainage, which was higher in the $\geq 50$ years old patients' group $(p=0.045)$. Additionally, there were other clinically significant results. The younger group of patients $(<50$ years $)$ seemed more prone to early complications $(21.1 \%$ vs. $4.2 \% ; p$ $=0.06)$, early prosthesis exposure $(13.2 \% \mathrm{vs.} 0 \% ; p=0.11)$ and readmissions ( $15.8 \%$ vs. $0 \% ; p=0.06$ ).

\section{Tobacco Use}

With respect to the characteristics of both groups ( - Table $\mathbf{1}$ ), smoking was more associated with patients aged $>50$ years $(p<0.001)$. DM was also more prevalent in the smoking group $(p=0.049)$.

With regard to the outcomes, there were no statistically significant differences (-Table 2). Despite this, there was a trend toward reconstruction failure being more frequent in the smoking group ( $28.6 \%$ vs. $14.9 \% ; p=0.24)$.

\section{Discussion}

Obesity is a significant public health problem in the Western world. It is considered a risk factor for the development of many prevalent cancers, including breast cancer, and affects survival in women diagnosed with this disease. ${ }^{11}$ Given the rising incidence of obesity worldwide, plastic surgeons increasingly face the difficult decision regarding the best option for breast reconstruction in this challenging population. ${ }^{12}$ Obesity seems to play a role in the disease, but its impact on short-term surgical outcomes has not been quantified. ${ }^{13}$ Higher failure rates with implant-based breast reconstruction occur in this population, particularly in immediate reconstruction. ${ }^{12}$

In our study, excess weight was associated with a higher frequency of early infections. Olsen et al, ${ }^{8}$ conducting a study on several types of breast surgery, also found that obesity was a risk factor for surgical site infections. Another study by Sinha et $\mathrm{al}^{14}$ regarding implant-based breast reconstruction also found higher values of BMI associated with a higher risk of infection. As expected, a higher volume of breast drainage and mastectomy flap necrosis were associated with overweight patients. Most of these patients have larger breasts, and after mastectomy (which also involves more dissection), there is a wider pocket to fill. The remaining skin flaps have a deficient vascularization when compared with smaller breasts, and it becomes even worse when a sizable implant is placed to fill all the dead space created. Interestingly, Lee et $\mathrm{al}^{5}$ found that ADM may protect against higher drainage volumes when the mastectomy specimen weight is greater than $400 \mathrm{~g}$. More studies are needed to support this idea.

We also observed a clear trend toward reconstructive failure being more associated with patients with $\mathrm{BMI} \geq 25$ (24.4\% vs. $11.7 \%$ ). Several studies show that BMI is an independent risk factor for major and early complications. . $^{16-10,15-19}$ Sadok et al, ${ }^{7}$ in a study concerning alloplastic breast reconstruction (immediate and delayed), found a risk for major complications 10 times higher in patients with $\mathrm{BMI} \geq 25$. Selber et al, ${ }^{18}$ in a large retrospective study with 564 patients submitted to alloplastic breast reconstruction with expander/implant and ADM, reported obesity and larger breast volumes as leading risk factors for explantation and early complications. We believe the results in our study were not statistically significant due to the low number of patients. Nevertheless, they are substantial enough to make us proceed with caution when pondering this kind of breast reconstruction for overweight patients.

The impact of age in implant-based breast reconstruction is still quite conflicting. Riggio et al, ${ }^{9}$ in an extensive series of 294 immediate alloplastic breast reconstructions, found that age did not increase the risk of complications in one-stage or two-stage reconstructions. On the contrary, McCarthy et $\mathrm{al}^{17}$ reported a 2.5 times greater risk of women over 65 years to develop complications. Interestingly, in this large study (1170 expander/implant reconstructions), age was not a significant predictor of reconstructive failure.

In our study, the only statistically significant result was the association of higher volume of total breast drainage with patients $>50$ years. Despite this, the duration of drainage was not substantially different between both groups. Unexpectedly, there was a trend toward higher early complications, reconstructive failure, and readmissions in the younger cohort ( $<50$ years). We cannot explain this result. August et $\mathrm{al}^{20}$ in a study with 242 patients, reported much higher rates of complications in patients younger than 60 years (64\% vs. $32 \%$ ) in implant-based breast reconstruction. Nevertheless, there was a massive discrepancy in the number of patients in both age groups ( 224 patients $<60$ years and only 18 patients $\geq 60$ years). We believe this creates a critical bias when comparing the outcomes.

Perhaps there may be other demographic or clinical variables not tested in our study which can influence the outcomes. Additional comorbidities like pulmonary or cardiac disorders, hormonal imbalances, or even chronic medication, like anticoagulants or steroids, might produce different results. Radiotherapy is also commonly associated with higher rates of major complications and reconstruction failure. ${ }^{9,18}$ 
The impact of smoking on breast surgery outcomes has been thoroughly analyzed, and most studies report it as a risk factor for major complications and reconstruction failure. ${ }^{15,17,21}$ In our study, smoking did not have any statistically significant impact on all outcomes tested. Despite this, the overall implant loss rate was $28.6 \%$ in smokers and $14.9 \%$ in nonsmokers. This result indicates that smoking might indeed affect the outcomes of this kind of breast reconstruction, but perhaps the power of our study was not strong enough to detect significant differences.

One of the main problems caused by tobacco is tissue hypoxia, which can lead to mastectomy flap necrosis and wound healing problems. Tasoulis et $\mathrm{al}^{2}{ }^{2}$ conducting a retrospective review of immediate breast reconstructions with implants/expanders and ADM (110 patients), did not find any association between smoking and postoperative complications. The authors pointed out that the mastectomy weight was small to moderate (185-335 g) in their sample and that the outcomes could have been different in patients with larger breasts. In our study, we did not evaluate the weight of the mastectomy specimen nor the degree of preoperative breast ptosis. Alderman et a ${ }^{10}$ also did not find a negative impact of smoking on breast reconstruction. In his series of 326 patients submitted to implant and autologous reconstruction, there was no association between smoking and total/major complications. The percentage of smokers in that study was $9.3 \%$.

In our study, the percentage of smokers was substantially higher than in these two studies (13.9\%). In fact, this percentage varies widely among the literature, between $2.1 \%$ and $24 \%$. ${ }^{514,19,22}$ This might be due to different cultural/social habits and also different ways of categorizing the same kind of patients. In our study, we separated active smokers (patients who smoked in the last month preop) and nonactive smokers. Consequently, the nonsmoker group can be quite heterogenous, including ex-smokers. Robust data regarding the amount of time necessary for smoking cessation to alter the risk of surgical complications is still missing.. ${ }^{21}$ Additionally, we did not quantify the number of cigarettes consumed per day in the smoking group. This might also impact the outcomes.

This study has several limitations. The retrospective nature, the limited number of patients, and the fact that it was conducted in a single center make it impossible to generalize the results. The short follow up time (6-12 months) does not allow us to make any statements regarding long-term outcomes. The study did not evaluate additional risk factors such as chemotherapy or breast size. We also need to acknowledge the potential presence of confounding variables. Regarding tobacco use, the self-report assessment obtained from the patients could have been flawed. We did not perform any objective evaluation to test for nicotine blood levels during the perioperative period.

\section{Conclusion}

Immediate breast reconstruction with implant and ADM offers satisfying results with few complications. Based on the results of our series, a BMI $\geq 25$ is a risk factor for early infection and reconstructive failure. Age over 50 years is associated with a higher volume of breast drainage but might even be protective for the development of early complications and early implant extrusion. Smoking does not appear to affect the outcomes significantly in this type of reconstruction. Taking into account these results, surgeons should consider delaying the reconstruction or using autologous tissue when patients are overweight. We believe this information can help other practitioners in their decision-making process regarding the kind of breast reconstruction offered to their patients.

\section{Availability of Data and Material}

The data was collected from the digital clinical files of the patients in Hospital IPO Porto in January 2020.

\section{Financial Disclosure Statement}

The authors have no financial interest or commercial association to disclose.

\section{Conflicts of Interest}

The authors have no conflicts of interest to disclose.

\section{References}

1 Remington AC, Gurtner GC, Wan DC, Nguyen D, Momeni A. Identifying risk factors for postoperative major complications in staged implant-based breast reconstruction with AlloDerm. Breast J 2019;25(4):597-603

2 Tasoulis MK, Teoh V, Khan A, Montgomery C, Mohammed K, Gui G. Acellular dermal matrices as an adjunct to implant breast reconstruction: analysis of outcomes and complications. Eur J Surg Oncol 2020;46(4 Pt A):511-515

3 Greig H, Roller J, Ziaziaris W, Van Laeken N. A retrospective review of breast reconstruction outcomes comparing AlloDerm and DermaCELL. JPRAS Open 2019;22:19-26

4 Israeli Ben-Noon H, Farber N, Weissman O, et al. The effect of acellular dermal matrix on drain secretions after immediate prosthetic breast reconstruction. J Plast Surg Hand Surg 2013;47(4):308-312

5 Lee KT, Hong SH, Jeon BJ, Pyon JK, Mun GH, Bang SI. Predictors for prolonged drainage following tissue expander-based breast reconstruction. Plast Reconstr Surg 2019;144(1):9e-17e

6 Lin KY, Johns FR, Gibson J, Long M, Drake DB, Moore MM. An outcome study of breast reconstruction: presurgical identification of risk factors for complications. Ann Surg Oncol 2001;8(7):586-591

7 Sadok N, Krabbe-Timmerman IS, de Bock GH, Werker PMN, Jansen L. The effect of smoking and body mass index on the complication rate of alloplastic breast reconstruction. Scand J Surg 2020;109(2):143-150

8 Olsen MA, Lefta M, Dietz JR, et al. Risk factors for surgical site infection after major breast operation. J Am Coll Surg 2008;207(3):326-335

9 Riggio E, Toffoli E, Tartaglione C, Marano G, Biganzoli E. Local safety of immediate reconstruction during primary treatment of breast cancer. Direct-to-implant versus expander-based surgery. J Plast Reconstr Aesthet Surg 2019;72(2):232-242

10 Alderman AK, Wilkins EG, Kim HM, Lowery JC. Complications in postmastectomy breast reconstruction: two-year results of the Michigan Breast Reconstruction Outcome Study. Plast Reconstr Surg 2002;109(7):2265-2274

11 Protani M, Coory M, Martin JH. Effect of obesity on survival of women with breast cancer: systematic review and meta-analysis. Breast Cancer Res Treat 2010;123(3):627-635 
12 Garvey PB, Villa MT, Rozanski AT, Liu J, Robb GL, Beahm EK. The advantages of free abdominal-based flaps over implants for breast reconstruction in obese patients. Plast Reconstr Surg 2012;130(5):991-1000

13 Chen CL, Shore AD, Johns R, Clark JM, Manahan M, Makary MA. The impact of obesity on breast surgery complications. Plast Reconstr Surg 2011;128(5):395e-402e

14 Sinha I, Pusic AL, Wilkins EG, et al. Late surgical-site infection in immediate implant-based breast reconstruction. Plast Reconstr Surg 2017;139(1):20-28

15 Thorarinsson A, Fröjd V, Kölby L, Lidén M, Elander A, Mark H. Patient determinants as independent risk factors for postoperative complications of breast reconstruction. Gland Surg 2017;6(4):355-367

16 Hirsch EM, Seth AK, Kim JYS, et al. Analysis of risk factors for complications in expander/implant breast reconstruction by stage of reconstruction. Plast Reconstr Surg 2014;134(5): 692e-699e

17 McCarthy CM, Mehrara BJ, Riedel E, et al. Predicting complications following expander/implant breast reconstruction: an outcomes analysis based on preoperative clinical risk. Plast Reconstr Surg 2008;121(6):1886-1892
18 Selber JC, Wren JH, Garvey PB, et al. Critical evaluation of risk factors and early complications in 564 consecutive two-stage implant-based breast reconstructions using acellular dermal matrix at a single center. Plast Reconstr Surg 2015;136(1):10-20

19 Woerdeman LA, Hage JJ, Hofland MM, Rutgers EJ. A prospective assessment of surgical risk factors in 400 cases of skin-sparing mastectomy and immediate breast reconstruction with implants to establish selection criteria. Plast Reconstr Surg 2007;119(2):455-463

20 August DA, Wilkins E, Rea T. Breast reconstruction in older women. Surgery 1994;115(6):663-668

21 Goodwin SJ, McCarthy CM, Pusic AL, et al. Complications in smokers after postmastectomy tissue expander/implant breast reconstruction. Ann Plast Surg 2005;55(1):16-19, discussion 19-20

22 Nahabedian MY, Tsangaris T, Momen B, Manson PN. Infectious complications following breast reconstruction with expanders and implants. Plast Reconstr Surg 2003;112(2):467-476 